MAKALAH

\title{
BERPIKIR SEJARAH DAN PERADABAN AWAL BENUA EROPA
}

Diajukan tugas untuk memenuhi tugas mata kuliah Sejarah Eropa

$$
\text { (AKBK2016) }
$$

Dosen Pengampu:

Dr. Mohamad Zaenal Arifin Anis, M.Hum.

Mansyur, S.Pd., M.Hum.

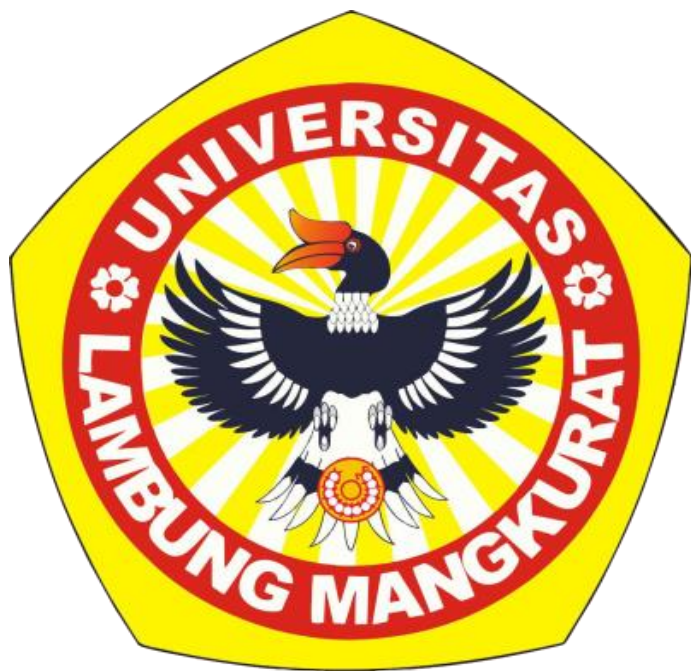

Disusun oleh:

Kelompok 1

Ella Noor Apriani $\quad 2010111220030$

Rabiatul Nita $\quad 2010111220003$

Lala Sapitri $\quad 2010111220034$

A1 Pendidikan Sejarah

PROGRAM STUDI PENDIDIKAN SEJARAH

JURUSAN PENDIDIKAN ILMU PENGETAHUAN SOSIAL

FAKULTAS KEGURUAN DAN ILMU PENDIDIKAN

UNIVERSITAS LAMBUNG MANGKURAT

BANJARMASIN 


\section{KATA PENGANTAR}

Segala puji dan syukur hanya milik Allah SWT, shalawat dan salam selalu tercurahkan kepada Baginda Kita Nabi besar Muhammad SAW. Berkat limpahan rahmat dan karuniaNya, penulis mampu menyelesaikan makalah ini yang berjudul Berpikir Sejarah dan Peradaban Awal Benua Eropa.

Adapun maksud penyusunan makalah ini diajukan untuk memenuhi tugas mata kuliah Sejarah Eropa. Rasa terima kasih yang tidak terkirakan kepada yang terhormat dosen pengampu Bapak Dr. Mohamad Zaenal Arifin Anis, M.Hum. dan Bapak Mansyur, S.Pd., M.Hum. selaku pembimbing materi dalam pembuatan makalah ini, serta semua pihak yang telah mendukung dalam penyusunan makalah ini yang tidak bisa kami sebutkan satu persatu.

Kami mengucapkan terimakasih kepada Bapak Dr. Mohamad Zaenal Arifin Anis, M.Hum dan Bapak Mansyur, S.Pd., M.Hum. selaku mata kuliah Sejarah Eropa yang telah memberikan tugas ini sehingga dapat menambah pengetahuan dan wawasan yang sesuai dengan bidang yang kami tekuni.

Kami menyadari bahwa makalah ini masih banyak kekurangannya karenanya kelompok kami berharap akan kritik dan saran yang bersifat membangun yang sangat kami nantikan. Demi perbaikan serupa dikemudian hari, semoga makalah ini bermanfaat untuk kelompok kami dalam menambah wawasan, dan semua yang telah membaca makalah ini.

Banjarmasin, 21 Mei 2021

Penulis 


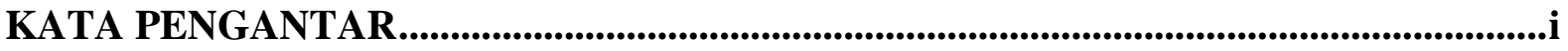

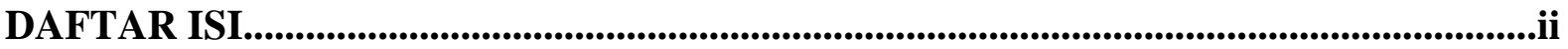

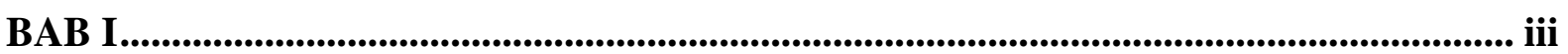

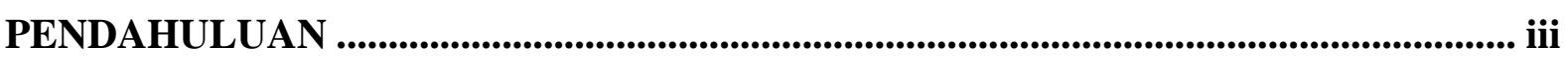

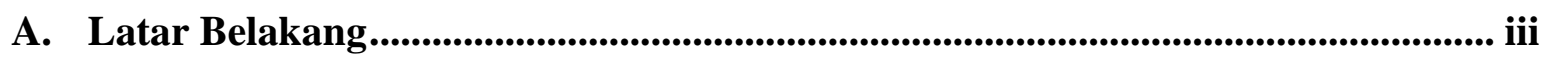

B. Rumusan Masalah .................................................................................................. ii

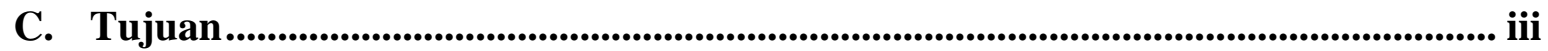

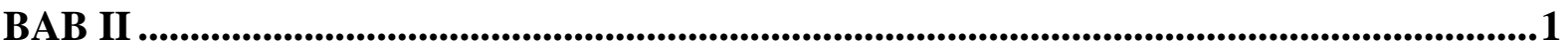

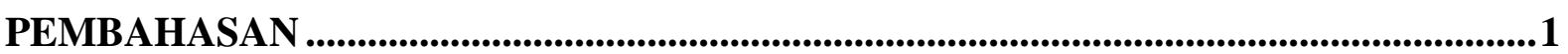

A. Berpikir Sejarah..................................................................................................................1

1. Hakikat sejarah sebagai ilmu ..........................................................................................1

2. Pemikiran sejarah ..................................................................................................................2

3. Cara berpikir dalam penulisan sejarah ...........................................................2

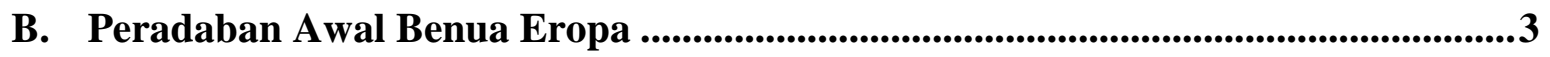

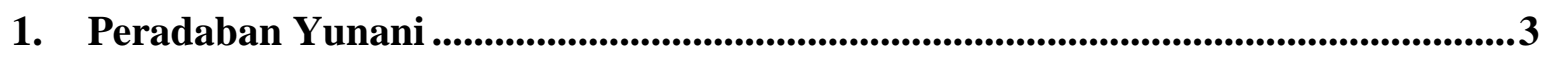

2. Peradaban Romawi ....................................................................................4

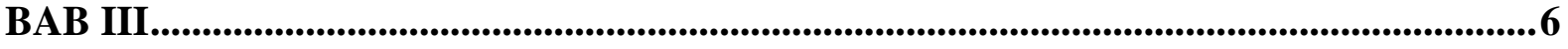

PENUTUP

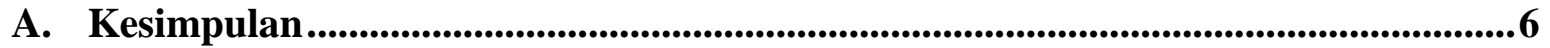

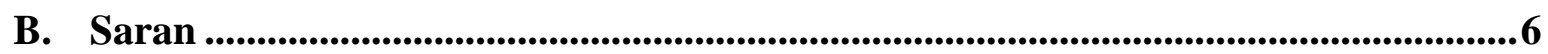

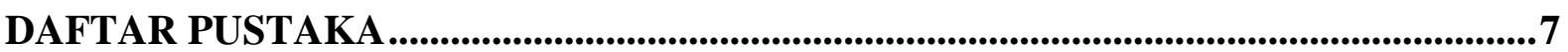




\section{BAB I \\ PENDAHULUAN}

\section{A. Latar Belakang}

Sejarah adalah ilmu yang memberikan dan menanamkan pengetahuan mengenai proses perubahan dan perkembangan masyarakat dari masa lampau hingga masa kini. Sejarah juga bisa digunakan sebagai sarana pembelajaran dalam kehidupan sehari agar bisa menjalani kehidupan hari berikutnya lebih baik daripada hari kemarin.

Sejarah sebagai ilmu mengajarkan kita, untuk selalu berdialog pikiran, sejarah juga menghubungkan masa lampau masa sekarang dan masa yang akan datang (Anis, M. Z. A. 2015: 53). Terdapat pengulangan peristiwa dalam sejarah meskipun pengulangan itu tidak sama persis seperti yang terjadi pada zaman dahulu sampai lahirnya peradaban. Pada umumnya tempat lahirnya peradaban tidak jauh dari sungaisungai besar, dan tepi laut, hail ini menunjukka bahwa air sebagai sumber kehidupan utama bagi manusia. Selain itu sungai dan pantai juga merupakan sarana perhubungan dengan bangsa lain.

Tingginya peradaban suatu bangsa ditandai dengan beragamnya hasil budaya yang lahir untuk memenuhi kebutuhan manusia. Manusia adalah pendukung kebudayaan, sehingga kebudayaan dapat dikatakan sebagai keseluruhan hasil cipta, karsa dan karya manusia. Ada banyak sejarah peradaban yang bisa kita pelajari untuk menambah pengetahuan kita, salah satunya yaitu peradaban Eropa.

\section{B. Rumusan Masalah}

1. Apa yang dimaksud dengan sejarah?

2. Bagaimana peradaban awal di Eropa?

3. Apa saja peninggalan-peninggalan dari adanya peradaban Eropa?

\section{Tujuan}

1. Untuk mengetahui apa itu sejarah

2. Untuk mengetahui peradaban awal di Eropa

3. Untuk mengetahui peninggalan-peninggalan dari adanya peradaban Eropa 


\section{BAB II}

\section{PEMBAHASAN}

\section{A. Berpikir Sejarah}

\section{Hakikat sejarah sebagai ilmu}

a. Bersendi pada pengetahuan

Syarat utama ilmu adalah bersendi pada pengetahuan. Tidak mungkin ada ilmu tanpa pengetahuan. Berarti pengetahuan adalah ciri pertama yang menjadi landasan ilmu untuk mencari keterangan atau penjelasan lebih lanjut tentang sesuatu. Suatu pengetahuan menjadi ilmu harus memiliki syarat-syarat yang mencakup subjek, objek, dan hubungan subjek dengan objek (Mardikaningsih et al., 2013)

b. Memiliki metode

Metode adalah salah satu unsur yang harus dimiliki oleh ilmu, penulisan sejarah tanpa dilandasi oeh metode sejarah hanya akan menghasilkan tulisan populer, uraiannya hanya bersifat deskriptif-naratif dan tidak menunjukkan ciri-ciri karya ilmiah sejarah (Mardikaningsih et al., 2013).

c. Sistematis

Uraian sistematis akan menunjukkan hubungan antara satu fakta dan fakta lain yang bersifat kausalitas (hubungan sebab akibat), karena sejarah merupakan suatu proses (Mardikaningsih et al., 2013).

d. Pendekatan ilmiah

Selain menggunakan metode dan teori sejarah, penulisan sejarah ilmiah dituntut untuk menggunakan pendekatan multidimensional (interdisipliner), yaitu penerapan konsep dan teori ilmu-ilmu sosial yang relevan dengan masalah sejarah yang dibahas (Mardikaningsih et al., 2013). Selain Pendekatan ilmiah itu perlu dilakukan karena tulisan sejarah ilmiah harus bersifat deskriptif-analsis, teori digunakan untuk mempertajam daya analisis sehingga diperoleh eksplanasi (kejelasan) mengenai berbagai hal, termasuk makna peristiwa (Mardikaningsih et al., 2013). 
e. Perspektif filsafat

Filsafat adalah landasan berfikir untuk menegaskan kebenaran ilmu. Pemikiran filsafat, khususnya logika berfikir dapat meningkatkan kualitas pengetahuan manusia. Oleh karena itu, sejarah sebagai ilmu juga memiliki filsafat sejarah. Perspektif sejarah itu digunakan untuk mencapai objektivitas dan kebenaran sejarah (Mardikaningsih et al., 2013).

\section{Pemikiran sejarah}

Dalam kehidupan manusia, peristiwa sejarah merupakan suatu peristiwa yang abadi, unik, dan penting (Mardikaningsih et al., 2013). Peristiwa-peristiwa sejarah yang ada itu hendaknya disusun dengan cara berpikir yang logis, cara berpikir yang logis pasti akan bersangkutan dengan logika, demikian pula sejarah sebagai sesuatu yang ilmiah dapat dikaji dengan logika, hal itu sejarah bukan mitos ataupun metafisika, berpikir logis sangat diperlukan dalam logika sejarah agar sejarawan tidak sekedar mengetahui melainkan dapat mengungkapkan dengan jelas dan cermat pengetahuan yang diperoleh dari fakta-fakta.

\section{Cara berpikir dalam penulisan sejarah}

a. Berpikir diakronis

Diakronis dapat diartikan sebagai suatu peristiwa yang berhubungan dengan peristiwa-peristiwa sebelumnya dan tidak berdiri sendiri atau timbul secara tiba-tiba.

b. Berpikir sinkronis

Berpikir sinkronis dalam sejarah adalah mempelajari peristiwa yang sezaman, atau horizontal.

c. Periodisasi

Periodisasi adalah pembagian atas dasar pengelompokkan, babakan zaman dan waktu tertentu didalam cerita sejarah.

d. Kausalitas

Kausalitas merupakan suatu rangkaian peristiwa yang mendahului dan peristiwa yang menyusul kemudian. Kausalitas merupakan prinsip sebab akibat.

e. Kronologi 
Kronologi adalah urutan peristiwa yang dimulai dari peristiwa yang terendah atau awal terjadi sampai yang terakhir terjadi.

\section{B. Peradaban Awal Benua Eropa}

\section{Peradaban Yunani}

a. Kondisi Geografis

Daerah Yunani terletak di ujung tenggara benua Eropa. Sebagian daerah kepulauan di laut Aegea dan laut Ionia juga termasuk wilayah ini. Di sebelah utara Yunani berbatasan dengan Albania, Yugoslavia, Bulgaria, dan Turki (Hapsari \& Syukur, 2008). Peradaban Yunani lahir di lingkungan geografis yang sebenarnya tidak mendukung. Yunani merupakan tanah yang keirng, dengan banyak benteng alam yang kuat berupa jurang-jurang yang terjal, gunung-gunung yang tinggi, serta pantai-pantai yang curam dan terjal. Hujan sangat jarang turun di Yunani. Bangsa Yunani terbentuk dari percampuran bangsa pendatang dari laut Kaspia dan penduduk asli yang terdiri atas petani. (Mardikaningsih et al., 2013).

b. Sistem Kepercayaan

Masyarakat Yunani memuja banyak dewa atau politeisme. Masyarakat Yunani mengambarkan dewa-dewa yang disembahnya bertubuh dan berperilaku seperti manusia. Bahkan, orang Athena sendiri menyatakan diri mereka sebagai keturunan ion, yaitu anak Dewa Apollo. Kebanyakan dewa Yunani digambarkan seperti manusia, dilahirkan namun tidak akan tua, kebal terhadap apapun, bisa tidak terlihat, dan tiap dewa mempunyai karakteristik tersendiri (Mardikaningsih et al., 2013).

c. Filsafat dan Ilmu Pengetahuan

Filsafat adalah buah pikiran dari para filsuf tentang manusia, kehidupan, dan lingkungannya. Filsafat Yunani pada umumnya menerangkan bahwa kesempurnaan dapat dicapai manusia hanya dengan melalui penyelidikan sendiri, ketajaman otak, pengendalian nafsu, serta keteguhan hati untuk berbuat baik Turki (Hapsari \& Syukur, 2008). Para filsuf yang terkenal dari Yunani yaitu Socrates (469-399 SM), Plato (427-399 SM), Aritoteles (384-322 SM). 
Peninggalan peradaban Yunani yang menonjol adalah bangunanbangunan kuil yang didirikan untuk memuja para dewa-dewi masyarakat Yunani. Misalnya kuil Parthenon yang terdapat di bukit Acropolis didirikan oleh Raja Pericles. Bangunan kuil lainnya adalah kuil Dewa Zeus. Bangunannya disebut Altis dan kuil ini berada di bukit Olympus.Tidak saja bangunan kuil yang menunjukkan bahwa orang Yunani telah memiliki peradaban yang tinggi. Ada juga bangunan teater, yang digunakan untuk mementaskan sandiwara. Seni teater berkembang dengan baik pada masa Pericles. Sandiwara pada masa itu ada dua jenis yaitu tragedi dan komedi.

e. Athena dan Sparta

Athena dan Sparta adalah dua Negara kota atau polis yang terkenal di Yunani. Sistem pemerintahan Athena digariskan oleh Solon (549 SM). Sementara itu, sistem pemerintahan Sparta digariskan oleh Lycurgus (625 $\mathrm{SM})$.

\section{Peradaban Romawi}

a. Kondisi Geografis

Wilayah Romawi pada awalnya berada di daerah semenanjung Apenia atau yang dikenal dengan wilayah Italia sekarang. Daerah Italia terdiri atas pegunungan dan dataran rendah. Dataran rendah ini merupakan daerah yang subur. Pada dataran rendah ini masyarakat Romawi hidup dalam kelompokkelompok dan menggantungkan diri pada hasil pertanian yang mereka usahakan. Menurut mitologi, Romawi didirikan oleh Romulus, yaitu saudara kembar Remus. Kedua saudara kembar ini disusui oleh seekor serigala, dan Romulus berhasil menjadi raja Romawi pertama setelah membunuh Remus saudara kembarnya. Bangsa romawi merupakan percampuran antara bangsa pengembara dan penduduk asli. Bangsa pengembara ini berasal dari daerah utara dan daerah padang rumput sekitar Laut Kaspia (Hapsari \& Syukur, 2008).

\section{b. Sistem Kepercayaan}

Seperti halnya bangsa Yunani, bangsa Romawi juga memuja banyak dewa Dewa tertinggi mereka adalah Dewa Yupiter yang memerintah dunia, Dewa Yupiter didampingi oleh permasisurinya yang bernama Yuno, dewa yang lain diantaranya adalah, Venus (dewi kecantikan), Neptunus (dewi yang menguasai laut), Fortuna (dewa keberuntungan), Vesta (dewa pelindung kota Roma), Yustisia (dewi keadilan). 
c. Hasil Budaya Romawi

Kebudayaan Romawi dibedakan atas dua tahap, yaitu masa sebelum masehi dan masa sesudah masehi.

Hasil budaya Romawi sebelum masehi yaitu kuil, istana dan rumah bangsawan, basilika, gedung teater, triumphal arch atau gerbang kemenangan, aquaduct atau jembatan air, limes (benteng pertahanan).

$>$ Hasil budaya romawi sesudah masehi yaitu cotacombe dan gereja. 


\section{BAB III}

\section{PENUTUP}

\section{A. Kesimpulan}

Sejarah merupakan ilmu pengetahuan yang berhubungan dengan cerita bertarikh sebagai hasil penafsiran kejadian-kejadian dalam masyarakat manusia pada waktu yang telah lampau atau tanda-tanda yang lain. Ilmu sejarah merupakan suatu ilmu yang mengkaji atau membahas suatu peristiwa, baik itu menyangkut tokoh ataupun masyarakat di masa lampau yang memiliki pengaruh besar terhadap kehidupan.

Cara berpikir sejarah berbeda dengan cara berpikir ilmu pengetahuan alam. Karena, cara berpikir sejarah akan selalu berkaitan dengan masa lampau, sedangkan ilmu pengetahuan alam akan berkaitan dengan masa sekarang. Sebagai suatu stui, sejarah meneliti sepanjang kehidupan manusia, yaitu sejak manusia pertama kali muncul di bumi ini hingga sekarang.

Sejarah sebagai ilmu tentu saja mempunya metode sendiri, yang harus digunakan oleh seorang sejarawan dalam menulis suatu peristiwa sejarah. Dengan menggunakan metode tersebut seorang sejarawan akan mampu merekonstruksi suatu peristiwa sejarah dengan objektif.

Yunani merupakan salah satu pusat peradaban tertua di Eropa. Yunani terletak di sekitar Laut Tengah yang sangat strategis dalam pelayaran. Peradaban Yunani lahir di lingkungan geografis yang sebenarnya tidak mendukung. Bangsa Yunani terbentuk dari percampuran bangsa pendatang dari Laut Kaspia dan penduduk asli yang terdiri atas petani.

Romawi kuno adalah sebuah peradaban yang tumbuh dari Negara-kota Roma yang didirikan di semenanjung Italia sekitar abad ke-9 SM. Selama keberadaannya selama 12 abad, kebudayaan Romawi berubah dari sebuah monarki ke sebuah republik oligarki sampai kekaisaran yang luas.

\section{B. Saran}

Sejarah sangat penting digunakan sebagai pelajaran, karena dengan adanya sejarah kita bisa menjalani kehidupan yang berkembang dari hari kehari, sejarah merupakan suatu pengalaman di masa lalu, dengan pengalaman tersebut maka kita bisa menjadi manusia yang lebih baik di masa depan. Adanya peradaban bisa mengajarkan kita bahwa kita harus berkembang dalam kehidupan agar tidak menjadi manusia yang merugi, dan mempunyai masa depan yang cerah. 


\section{DAFTAR PUSTAKA}

Anis, M. Z. A. (2015). Sejarah Bukan Warisan Melainkan Pembelajaran.

Mardikaningsih, R., Sumaryanto., \& Karyanti, T., (2013). Sejarah Iuntuk Kelas X SMA dan MA Kelompok Peminatan Ilmu-Ilmu Sosial. Solo: PT Wangsa Jastra Lestari.

Hapsari, R., \& Syukur, A. (2008). Eksplorasi SEJARAH Indonesia dan Dunia UNTUK SMA KELAS X. Syarifudin, M (Ed). Jakarta: Penerbit Erlangga. 